Ciencia y Sociedad, Vol. 44, No. 3, julio-septiembre, 2019 • ISSN (impreso): 0378-7680 • ISSN (en línea): 2613-8751

DOI: https://doi.org/10.22206/cys.2019.v44i3.pp69-80

\title{
LA MATANZA DE HAITIANOS EN 1937 EN REPÚBLICA DOMINICANA PERSPECTIVA TRANS-TEXTUAL Y TRANS-DISCURSIVA
}

\section{The killing of Haitians in 1937 in the Dominican Republic}

\author{
Manuel Matos Moquete \\ Universidad Autónoma de Santo Domingo (UASD), República Dominicana. Correo-e: matosmoquete@hotmail.com
}

Recibido: 25/6/2019 • Aprobado: 20/8/2019

Cómo citar: Matos Moquete, M. (2019). La matanza de haitianos en 1937 en República Dominicana. Perspectiva transtextual y transdiscursiva. Ciencia y Sociedad, 44(3), 69-80. https://doi.org/10.22206/cys.2019.v44i3.pp69-80

\section{Texto-señuelo}

En un ensayo reciente, titulado La masacre, Pedro Conde Sturla (2019) emplea un recurso mimológico para describir la matanza de los haitianos de 1937, mediante la imitación del ruido de los machetes en el corte de la caña: la expresión cha cha cha:

El cha cha cha comenzó oficialmente en octubre del año 1937. La noche del 2 de octubre de 1937. De noche tenía que ser, al amparo de las sombras. Cha cha cha. Y luego durante días cha cha cha. Trujillo mismo anunció el inicio de la matanza y le pondría el nombre. Cha cha cha. (párr. 1)

Ese texto de Conde Sturla es producto de una relectura de otros textos. El autor está consciente de que esa imitación está enraizada en una oralidad dominicana, capaz de recrear la idea del corte del machete mediante esa figura onomatopéyica. Sabe también que, en contraste con el motivo lúgubre del texto, está aludiendo a la melodía de un ritmo musical denominado Cha cha cha.

El autor no ignora que de alguna manera también está aludiendo a dos obras de las que hay indicios en ese texto. La palabra “corte” es la expresión simbólica de la matanza en El Masacre se pasa a pie, del dominicano Freddy Prestol Castillo; la expresión "cosecha de haitianos" utilizada por Conde Sturla en ese texto es un injerto de la expresión Cosecha de Huesos, con la que metafóricamente la autora haitiana, Edwidge Dandicat, titula su novela acerca de la matanza de haitianos en República Dominicana.

En ese ensayo también se cita indirecta, pero claramente, la obra Trujillo: La vida y los tiempos de un dictador caribeño de Robert D. Crassweller y también el discurso de Trujillo en la casa de Isabel Mayer, en el cual justifica la matanza. 
En fin, son incontables las referencias orales y escritas comprimidas en ese texto, publicado por Conde Sturla el primero de julio de 2019, cuando el hecho histórico de la matanza de 1937 ya se ha incorporado al debate y al anecdotario del pueblo dominicano; por supuesto, también del pueblo haitiano. Y cuando ha sido objeto de tantos estudios y comentarios que, directa o indirectamente, aluden a la matanza de haitianos ejecutada por la dictadura de Rafael Leonidas Trujillo en 1937.

En lo que hasta ahora llevo dicho, importa mucho el texto de Conde Sturla, pero en realidad es un texto-señuelo que me permite develar la estrategia de este trabajo: abordar la masacre de 1937 como un hecho factual histórico, cuya significación se ha construido y ha de entenderse en el contexto de los discursos en torno a las relaciones dominico-haitianas.

\section{Trans-textualidad}

La lectura del texto de ese autor solo me ha servido como ejemplo para la aplicación del procedimiento denominado inter-textualidad, definido por el autor francés Gerard Genette (1982) como "una relación de copresencia entre dos o más textos" (p. 8), la cual se expresa usualmente en la cita, el plagio y la alusión.

Ese procedimiento es muy común en la literatura y en la investigación bibliográfica. Asimismo, la meta-textualidad, presente también en el texto de Conde Sturla, consiste en la relación de "«comentario»que une un texto a otro texto" Genette (1982), y de la cual se vale, regularmente, todo tipo de lectura y estudio en torno a las obras, como se practica en la crítica literaria. Esa relación se manifiesta también en forma más velada como señala Genette (1982), cuando se "habla de él sin citarlo (convocarlo), e incluso, en el límite, sin nombrarlo." (p. 10)

Ambos procedimientos, y otros más, forman parte de la amplia red textual bautizada por Genette como trans-textualidad, que implica "todo lo que pone al texto en relación, manifiesta o secreta, con otros textos" (1982, p. 7). Son procedimientos que recientemente empleé con gran provecho en mi investigación Discurso y acción: Manolo, Caamaño y El Moreno (2018).

Ahora, abordaremos el tema de la matanza de haitianos de 1937 durante la dictadura de Trujillo y su relación con la literatura dominicana, amparándonos en esos conceptos procedentes de la poética de Genette, a fin de mostrar el amplio campo de las relaciones textuales en el cual se han ido construyendo las representaciones y los sentidos de la matanza de 1937.

Es un proceso de significación que no comenzó ni puede terminar con la obra El Masacre se pasa a pie, de Freddy Prestol Castillo (1973). Sin embargo, ese texto está en el centro de la resignificación del hecho histórico y de los aspectos de las relaciones entre República Dominicana y Haití.

Hay que hablar forzosamente de esa obra, porque en la literatura dominicana ella acapara la temática. La producción literaria de autores dominicanos acerca de la relación dominico-haitiana, en general, es muy pobre; ha sido recreada muy escasamente, y en particular, la matanza de 1937.

El Masacre se pasa a pie, además, es el eje central de la trans-textualidad en la producción bibliográfica literaria y no literaria en torno al tema. Esa obra es, a la vez, receptora y productora de discursos inter-textuales y meta-textuales. Fue, según señala el autor, escrita en la época de aquel acontecimiento, pero publicada en 1973. En ese lapso hubo la posibilidad de consultar fuentes y enriquecer la obra variando y ampliando la perspectiva del borrador inicial.

Es pues pertinente y significativo situar los textos literarios como El Masacre se pasa a pie, cuyo universo gira en tono a la matanza de haitianos ordenada por Trujillo en 1937 y, en general, a las relaciones entre República Dominicana y Haití, en el conjunto de los discursos acerca de las relaciones entre las dos naciones que comparten la isla. 
Mi novela La avalancha, la cual trata sobre la migración haitiana en nuestro país, tomando como universo el lugar capitalino denominado Petit Haití, se sitúa en una relación de inter-textualidad con $E l$ Masacre se pasa a pie.

De ahí que un crítico, José Carvajal (2015), ha afirmado lo siguiente:

En términos generales, por tratar el tema de la presencia haitiana en territorio dominicano, "La avalancha" puede verse como una obra hermana de "El masacre se pasa a pie" (1973) de Freddy Prestol Castillo. Narra la transformación de un distinguido sector de Santo Domingo en un gueto de inmigrantes del país vecino que arrastran hasta ese lugar una forma de vida distinta, a partir de la presencia de un haitiano (Honson Baliat) que llega huyendo de un batey «junto a una banda de forajidos congos." (p. 1)

Pero también están vinculadas como intertextos con El Masacre se pasa a pie, las novelas de autores haitianos sobre la matanza, y en general, que abordan aspectos comunes o diferentes entre la cultura haitiana y dominicana, especialmente Jacques Stephen Alexis, Mi compadre el general sol (1957), Edwidge Danticat, Cosecha de huesos (1998) y René Philoctète, Le Peuple des Terres Mêlées (1989) (La gente de las tierras mixtas).

También guarda relación de inter-textualidad con la novela de Prestol Castillo, un conjunto de obras dominicanas en las que la masacre del 37 no es un motivo, sea por la cronología o sea porque es un tema tabú que debe ser fichado con el valor de ausencia, supuesto, vacío, inciso, metáfora.

Me refiero a la poesía negroide de Manuel del Cabral, como los poemas "Negro sin nada en casa", "Negro sin zapato", de Rubén Suro, como el poema "Rabiaca de un haitiano que espanta mosquitos"; así como las obras de otros poetas, poetas que se inscriben en esa orientación. Quisiera destacar un poema ejemplar de simbiosis cultural y racial del negro y el blanco: "Yelida", de Tomas Hernández Franco.
La crítica literaria no ha estado ausente como metatexto en el tratamiento de la relación dominico-haitiana. Pura Emeterio Rondón publicó dos importantes obras de estudio comparado entre la literatura dominicana y la haitiana: Ética y estética en el mito literario (en República Dominicana y Haití) (2000) y Narrativas dominicana y haitiana: simbolos para una propuesta alternativa (2007).

Otros críticos literarios han tratado el tema dominico-haitiano. Se refieren al hecho histórico de la matanza del 37 como tal, o a la obra El Masacre se pasa a pie: entre ellos, Iván Grullon, ex rector de la Universidad Autónoma de Santo Domingo (UASD) publicó una obra en la editora de esa universidad, La matanza de los haitianos en El Masacre se pasa a pie y Mi compadre el general sol (1989).

Diógenes Céspedes ha tratado ampliamente ese tema en diversos trabajos, pero de quien solo quisiera mencionar el texto "Origen de los conflictos domínico-haitianos a través de los discursos histórico-literarios" (Areito, 2014). Andrés L. Mateo reserva un gran espacio al tema dominico-haitiano, en particular a la matanza de 1937 en su obra Mito y cultura en la era de Trujillo (2004).

La relación dominico-haitiana es tema central de las obras de Manuel Núnez, El Ocaso de la nación dominicana (2001) y Peña Batlle en la Era de Trujillo (2007). Odalis Pérez dedica una obra a ese tema, La ideología rota: el derrumbe del pensamiento pseudonationalista (2002), Diógenes Abreu es autor de un ensayo vinculado al tema, Perejil: el ocaso de la hispanidad dominicana; celebración de la multiplicidad cultural desde New York, Ibeth Guzmán presentó recientemente una tesis doctoral sobre el tema; y algunos estudiantes dominicanos en el extranjero han dedicado sus trabajos de finalización de estudios doctorales al tema dominico-haitiano.

Si es importante la bibliografía en la crítica literaria - mucho menor en la ficción-, superior es en el campo de las ciencias sociales, como se puso de relieve en "Coloquio Internacional Sobre la Cuestión Haitiana en República Dominicana", celebrado 
en Santo Domingo durante los días 2, 3 y 4 de diciembre de 1991. Entre los trabajos presentados en ese evento debemos destacar las ponencias de Frank Moya Pons y de Bernardo Vega, recogidas en la obra La cuestión haitiana en Santo Domingo, (Wilfredo Lozano, 1996).

En razón de que Haití y Santo Domingo han sido importantes desde la colonización en la estrategia geopolítica de grandes potencias, la bibliografía internacional en español, francés e inglés sobre las relaciones dominico-haitianas es aún más amplia que la estrictamente dominicana.

La bibliografía literaria y la no literaria de autores dominicanos, que son las que ahora nos interesan, tienen en común un rasgo que es preciso resaltar: la subjetividad. Subjetividad individual de los autores y la trans-subjetividad colectiva y cultural propia de los habitantes del lado oriental de la isla cuando se refieren a los habitantes del lado occidental. Es lo que se destaca en la obra El otro del nosotros, sobre el prejuicio antihaitino en Santiago de los Caballeros, fruto de una investigación dirigida por Arturo Jimenes Sabater y publicada por el Centro de Estudios Padre Juan Montalvo (1995).

\section{Trans-discursividad}

Los textos son manifestaciones de los discursos. Para un tipo de discurso puede haber diferentes tipos de texto. Y así, la trans-textualidad, la inter-textualidad, la meta-textualidad y otros tipos de relaciones textuales tejen relaciones trans-discursivas.

Somos discursos, hechuras de discursos, que habitualmente los historiadores llaman "hechos". En la transdiscursividad de las relaciones dominico-haitianas coexisten varios tipos de discursos, entre los cuales, por ahora, interesan los siguientes: el discurso de independencia nacional o la separación de Haití, que comprende los aspectos geopolítico e históricos que delimitan las dos naciones; el discurso de la identidad del dominicano, que se distingue por la búsqueda de definición y diferenciación del pueblo haitiano en términos de origen o procedencia, raza y cultura, y en esta última instancia, lengua, religión, música, baile, costumbres, modo de vida, etc.; y el discurso migratorio o de la migración de los haitianos en nuestro país, que involucra elementos como la mano de obra, el régimen de contratación, condiciones de vida y de trabajo, y los derechos de los migrantes, incluyendo los de residencia y nacionalización.

Esos discursos conforman lo que Moya Pons (1996) denomina la "literatura de la frontera", concepto que ese autor divide en los aspectos histórico, político y social:

La literatura de la frontera puede dividirse claramente en tres grandes ciclos que yo quisiera llamar de la frontera histórica, la frontera politica, y la frontera social, pues las obras sobre el tema han sido producidas en tres grandes oleadas que forzosamente nos hacen ver en esa dirección. (p. 21)

Los discursos de las relaciones dominico-haitianas, o de la frontera, según Moya Pons, se interrelacionan en un contexto más amplio, conformando una transdiscursividad histórica: desde el surgimiento de ambas naciones, un todo integrado por los discursos y textos orales y escritos, literarios y no literarios acerca de las relaciones dominico-haitianas.

Esos discursos están presentes en la novela El Masacre se pasa a pie como parte del conjunto del contexto trans-discursivo que hemos venido describiendo. Pero también estuvieron en la masacre de 1937 presidiendo sus motivaciones. Y están presentes hoy en las tomas de posición con respecto a los diferentes asuntos de las relaciones entre los dos países.

Entre esos discursos, los hay de simpatía y de antipatía respecto a los haitianos; los prejuiciados y desprejuiciados. Hay discursos declarados y burdos, pero también discursos elegantes y sutiles. Sin embargo, en el funcionamiento de esos discursos, no son las cuestiones principales. 
Lo principal es que, de todas maneras, esos discursos se sitúan y nos sitúan en una agenda que nos lleva a adoptar determinados puntos de vista; a situarnos en un aquí y ahora; a declarar una parcialidad indispensable o un sesgo irremediable, que de manera invariable permea el tratamiento de las relaciones dominicano haitianas.

Esos discursos instauran una subjetividad y una trans-subjetividad que están en el centro de los libros de historia y de las opiniones corrientes de cada uno de nosotros. Como afirmamos en otro texto, Matos Moquete (2005), la agenda a que nos referimos es un contexto discursivo que parece obligar a cada uno de nosotros a situarse en relación con estas preguntas:

¿Es o no la isla una e indivisible? ¿ Son o no son los dominicanos y los haitianos un mismo pueblo? ¿'Son diferentes? ¿Deben o no deben unirse o fundirse los dos Estados-pueblos? ¿Qué otros tipos de relación deben mantener? ¿De colaboración? ¿De confrontación? ¿Cree usted que los haitianos nacidos en República Dominicana son dominicanos y por tanto debe otorgárseles la nacionalidad? (p. 249)

Otras preguntas tienen cabida en esa agenda, en función de las circunstancias del momento.

Ahora, quisiera que nos acompañen a observar, brevemente, cómo cada uno de los discursos señalados se manifiesta en la novela El Masacre se pasa a pie, y cómo dicha obra se sitúa en el juego de la trans-textualidad con otros textos con base en esos discursos.

\section{Discurso migratorio y de la nacionalización de los migrantes haitianos}

Me referiré a ese discurso situándolo hoy en la sentencia 168-13. Formulé la pregunta del cuestionario anterior " $i$ Cree usted que los haitianos nacidos en República Dominicana son dominicanos y por tanto debe otorgárseles la nacionalidad?" en 2005, cuando no se pensaba la sentencia 168-13 emitida el
23 de septiembre del 2013 por el Tribunal Constitucional de República Dominicana, en la cual se establecía que los descendientes de personas extranjeras residentes irregularmente en el país desde 1929 no tenían derecho a la nacionalidad dominicana.

Como se observa, el problema de la nacionalidad de los descendientes haitianos no ha cesado de replantearse en cada momento. Renace como la Hidra de Lerna en la mitología griega, a través de sus múltiples cabezas. Y como conversación trae conversación —así me enseńó un amigo campesino-, un texto trae y atrae a otro texto; por tanto, la "sentencia" a la novela de Prestol Castillo, la novela a la "sentencia", pues no se sabe cuál de los dos textos tiene raíces más profundas.

La inter-textualidad da sentido enfático por repetición y ampliación a ese problema. La "sentencia" no ignora la masacre de 1937 puesto remonta sus efectos retroactivos hasta 1929, Prestol Castillo ha tenido que reseñar en su obra, como si fuera hoy, el drama de la nacionalidad de los haitianos; pues, como se observa en estos pasajes, la nacionalización fue uno de los problemas que motivó la acción de Trujillo contra los haitianos.

Se lee en la novela El Masacre se pasa a pie

La "cédula" —un documento de identificación exigido por las leyes de Santo Domingo- sería el pretexto. Iban los soldados bajo el pretexto de la búsqueda de infractores a la ley que obligaba a portar el documento identificatorio y arreaban grandes masas de haitianos hacia los llanos lejanos. (1973, p. 31)

A un desdichado no le valió o implorar que era dominicano y ofrecer dinero:

"Gritos de horror callados por la trágica muerte. Espanto, estertores. I silencio. I otra vez los gritos de los otros a quienes les llegaba el turno. Uno grita:

-No matá a mí... ¡Yo dominiquén!...”

-No matá... tomá cuátt (ofrecía dinero). 
-Gritaba un soldado, ebrio, endemoniado

-Levanta el brazo... pảmatá pronto!... maldito "mañé!"

-Ah, bon dieu!... y caía." (p. 32)

Y a Yosefo, no le sirvieron su fortuna hecha en suelo dominicano, haberse casado con una dominicana, procrear una extensa familia dominico-haitiana y haber obtenido sus papeles que lo declaraban como dominicano:

\section{Cuenta Prestol Castillo:}

Esta es la historia. Cuando los iban a matar a todos, el sargento Pío había detenido la horda de presidiarios.

Yosefo Dís, y sus hijos, debían vivir. Desde luego, esas gentes debían irse a Haití.

Es un diálogo que detiene los puñales. ¿Por qué?.. Claro: Manuelita es dominicana y ha procreado una familia de siete, con Yosefo, el haitiano más rico en yerbas y ganados. Pero no es su riqueza, ya pillada - los presos vaciaron sus estancias y ya las vacas van para la hacienda del Capitán, en Mao- lo que salva a Yosefo y a sus negros.

Es que la dominicana Manuelíita es hermana natural del sargento Pío. El Sargento y Yosefo son compadres. Había bautizado a François, el mayor.

-... Bueno... Yosefo... yo tor violando la ler! Tor violando la ler!... y váyanse pa Harti!... ahora mismo!...

Recoge tus trastos y tus hijos pa poneilos en la raya. Ante de que vengan otros!...

Yosefo casi no entiende... Dejar a "Castellanos"... "Su" tierra! Cuando vino, era pobre. Ahora debía dejar aquella tierra, dejarlo todo y venir en dos mulas con los hijos y unos pocos trastes. Debía dejar el dinero, las vacas, los cerdos, que eran muchos. Ahora debía irse a Haití. ¿A qué? A pasar hambre.

Manuelita no ha escuchado las palabras del Sargento y grita lastimeramente.

-No me maten mis hijo!... ¡Cójanlo tóo!... ¡Qué abuso! y el probe Yosefo, que se había hecho dominicano!... ayer mimo recebió los papele de la capital, de un Menisterio!...

Los papeles dicen que ya Yosefo es de aquí, como nosotros!... Y la casa.... y los animales... tanta lucha...

Qué abusol Qué abuso!"

-Manuelita... Manuelita, dice el Sargento. ¡Tate quieta!

Tate quieta! que tú sabes que son óidenes del "Supirioi Cumando"... de lo jefe grande!.... Tate quieta, que tú ere dominicana!...

-Y mis hijos... y Yosefo. (Hablaba con angustia y decisión). Quería huir y también deseaba morir.

El sargento Tarragona la dejó hablar e imprecar. Entre tanto, ordenó aderezar dos mulas y dos burras. Allí trepó los hijos. a Yosefo y a Manuela.

Cuando ésta montó, le dijo dos palabras, con enternecimiento:

-Adiós, mi hermana! ¿Qué, se va a hacé! (Entonces. parecía un condenado). Lloraba. Y volvía a mirar, ya lejana, a la hermana, que iba a un país desconocido. (p. 61)

La expulsión, la expatriación hacia Haití. Ese es el drama de toda la familia dominico-haitiana de Manuelita y Yosefo. Es una larga y trágica historia en el país.

Y ese texto de Prestol Castillo se inscribe en una narrativa que ha sido contada por autores del campo de 
las ciencias sociales, entre los cuales destaco estos títulos, que junto a muchos otros conforman una red inter-textual del discurso migratorio: Lemoine, M. (1983), Azúcar amargo; Lozano, W. (1992), La cuestión haitiana en Santo Domingo: Migración internacional, desarrollo y relaciones inter-estatales entre Haití y República Dominicana; Lozano, W. (2008), La paradoja de las migraciones: el estado dominicano frente a la inmigración haitiana; Evertsz, F. B. (1983), El azúcar y su problemática; Silié, R., Segura, C. C., y Cabral, C. D. (2002), La nueva inmigración haitiana.

\section{Discurso de la independencia}

La independencia nacional es el más importantes de los discursos de las relaciones dominico-haitianas. Es el que más nos enseñan en la escuela y en la vida del dominicano, pues es el que nos define como pueblo y como nación. Aquí se incluyen los textos y los símbolos patrios, desde el juramento de los trinitarios, el trabucazo de Mella y el himno nacional. Por tanto, no es necesario abundar, y solo decir que ese discurso fue enarbolado como la motivación principal de la matanza del 1937: la defensa de la patria producto de la invasión pacífica de los haitianos.

En El Masacre se pasa a pie ese discurso es omnipresente, y se encuentra mezclado con el discurso migratorio y el de la identidad. Se integran los demás, como se observa en algunos pasajes.

En este se habla de la "Geografía Patria":

El maestro había pronunciado una palabra rara: "Dajabón"... Se refería a una aldea lejana de mi país. Era en la clase de "Geografía Patria" y tratábase de límites entre la República Dominicana y la República de Haití, ambas en la Isla Hispaniola o de Santo Domingo, una de las grandes Antillas, en el mar Caribe. (p. 17)

En este se alude a una batalla por la independencia "Capotillo":
Acaso temblará al conversar con cualquier sargento o presidiario, ebrios, en algún baile en la aldea de "Capotillo". Allí, el sargento Tarragona. Gran acordeonista, tocando el "Juangomero" - una música excitante de la Línea- le hablaría de los degollados, con la misma placidez deportiva de un universitario al narrar entusiasmado sus triunfos en el estadio de volley-ball. (p. 63)

En este otro se evoca la ocupación haitiana en la expresion "-Toussaint va vuelva pa mandá dominiquén!..”":

Un día, cuando Juan Nazario, el dominicano, concubino de su hija, le enrostró que el haitiano "es un perro sarnoso", él calló, mientras musitaba, bajito:

-Toussaint va vuelva pa mandá dominiquén!..

(Toussaint va a volver a mandar a los dominicanos). Pero Juan Nazarío, el dominicano, no entendía estas palabras. Ahora hay sangre de dominicanos en la casta de Mustalí. I el viejo es una "cosa" inútil en el rancho. Su hija, mujer de Juan Nazarío, no supo, como Mustalí, quién fue Toussaint. Pero ella odia al dominicano. Por su parte, su marido, Juan Nazario, en momento de ira, especialmente cuando los haitianos roban su conuco o sus reses, truena:

En este pasaje el discurso de la independencia evoca la guerra, la lucha entre los dos pueblos y es reforzado por el discurso de la identidad: el haitiano ladrón, "negros sucios, que jieden a pájaro muerto" "país maldito", "maldita raza!....

—iMalditos negros éstos!... que debían matarlos a tóo!... Pa que se larguen de una vez!... No vale criá... tó se lo llevan!... no vale sembrá, que se lo roban too ... y yo, dominicano, hasta me he separao de mi país al meterme con estos negros sucios, que jieden a pájaro muerto! Estoy loco porque se arme una bronca con Haití, pa dentrá a ese país maldito, cortando cabeza y 
barriga hasta Puerto Principe... pa acabá de una vez con esta maldita raza!.. (p. 76)

Bajo este árbol frondoso donde pasamos un rato de la siesta, esquivando un sol de fuego, pienso en la agonía de Haití, despreciado aún por los dominicanos negros.

Vemos estos inmensos prados de la frontera y asalta una pregunta: ¿¿De quién es esta tierra?... Enantes, abandonada. Luego cultivada por Haití, que la pobló de estancias y frutales — cafetos, aguacates, mangos, sombríosy ahora desolada, bajo crimen. ¿Para qué? ¿Quién vendrá a esquilmar estos cafetales abandonados, estas praderas vacías?...

Los dominicanos apenas mantuvieron posesión en las tierras. A ellas apenas llegaba la revolución. Después de los conquistadores y las cruces monásticas de la Colonia. Una soledad mantuvo alejadas estas regiones del aliento nacional. Las lides revolucionarias llegaban a "Juan Calvo". "Cerro de las Mercedes". "Chacuey", "La Guajaca”. Solo en la Restauración llegaron soldados dominicanos a estas cumbres. Allí quedaban los muertos y luego un silencio eterno. (p. 90)

La bibliografía en este tipo de inter-textualidad es enorme, pero hay algunos textos que, a mi entender, sirven de referencia en el estudio del discurso de la independencia nacional: Balaguer, J. (1984), La isla al revés; Cassá, R. (1986), Actualidad y perspectivas de la cuestión nacional en la República Dominicana; Catrain, P., y Oviedo, J. (1983), La cuestión nacional y la conformación del Estado en República Dominicana. Santo Domingo; Chez Checo, J. (1997), La República Dominicana y Haití: Sintesis histórica de su problema fronterizo.

\section{Discursos de la identidad}

Hace unos años, en 1914, Julia declaraba que: "Cuando yo no quería irme a dormir, me decían que el hombre del saco haitiano —el Cuco- vendría por mí y a comerse a los niñitos dominicanos", dijo Álvarez. "Tú crías a un niño con este tipo de historias en su cabeza, y subliminalmente está aterrado, porque eso cala muy hondo".

Mi madre, Rita Moquete, no quería saber de trabajadora doméstica de nacionalidad haitiana. Cuando sus hijos la contratábamos no la aceptaba. Si se la imponíamos, su rechazo la llevaba a no comer la comida que ella cocinaba y la vigilaba en todo momento. Al poco tiempo decía: "A esa señora la tengo que botar, que el que brega con haitianos brega dos veces."

Y, sin embargo, mi madre era un alma de Dios, una bella persona. Pero como Julia Álvarez y como yo, y la mayoría de los dominicanos, se educó con la idea de que los haitianos son malos.

El discurso de la identidad fue el más apasionado y motivador de la masacre de 1937. Es un discurso que adquiere un gran énfasis en la obra El Masacre se pasa a pie. En contra de los haitianos se esgrimen la raza, la cultura, la lengua, la moral, etc., en un tono peyorativo y violento, como se observa en diferentes pasajes de esa obra.

La idea del haitiano ladrón, tópico que se repite:

Los tiempos habían cambiado para Juanico. Había desaparecido el ganado; de una parte, por las guerras, las "revoluciones", que mataban reses y hombres. Otra causa de extinción del ganado era el robo de los haitianos.

Decía Juanico hallarse en la miseria, pero era simple traza campesina. Propietario de las mejores tierras desde "La Carbonera", "Joussard", "Doña Maria", "Santiago de la Cruz" hasta "Partido" y "Vaca Gorda", término de su gran hato rustico, donde jamás había sembrado una mata de hierba.

Ahora andaba con un gran reloj, "líontína" y una gran cadena de oro en el bolsillo; su "cachimbo", un roto sombrero de alas enormes y un "sable de cabo", terciado. 
-Yo tengo que jablay con ei Generai... eto "mañese" (los haitianos) me han acabaol... Ya no me para una "salea" ni una becerra... No tengo una res... y de ante, no podía caminai por la sabana... poique antonce no era má que una mancha prieta de ganao... Ah! «mañeses» del Diablo!... Anteanochen estubién aquí, y no quedó un rabo e yuca pa los probe negros jijo mío... y pa mí tengo, que los haitianos trabajan con el Diablo!... Caminan con la noche como de día... (p. 36)

Labios gruesos mala articulación del español:

Vacas tristes, —¿por qué me parecían tristes las vacas? - "maicoté" y sol. Ahora no hay peones haitianos. El haitiano desapareció desde que el capitán Ventarrón inició El Corte”. “El Cortel” ¿Qué temblor y pavura vi en más de un labio grueso, afro-español, y en más de una articulación de sonidos ambiguos, pugnando por hablar claro el espańol, para demostrar que era dominicano quien "hablaba! (p. 27)

En este extenso fragmento, que describe el acto de la matanza, se percibe un conjunto de apreciaciones peyorativas sobre las víctimas: "maldito mañé!", "negro el diablo!”, "garrapata”, “estos negros, son bueno... Pero son ladrone! Deben morir!”

La sabana es inmensa. La "cédula" —un documento de identificación exigido por las leyes de Santo Domingo - sería el pretexto. Iban los soldados bajo el pretexto de la búsqueda de infractores a la ley que obligaba a portar el documento identitatorio y arreaban grandes masas de haitianos hacia los llanos lejanos. Lejos de las aldeas podrán realizar más ampliamente el festín homicida. Los haitianos iban mansos, en filas largas. Viejos, como Tamí, el limosnero; jóvenes y muchachas de carnes duras y fuerte grajo. Colores varios en las rústicas vestimentas.

Por su parte, los soldados tragaban ron repetidamente.
-Muchachos... romo! ...romo! que vamo a trabajai, decía el Sargento, mientras saludaba militarmente a los soldados, casi sin levantar el rostro. Todos bebían.

Los negros iban a cumplir una sentencia de muerte, sin protesta. Sabían que toda clemencia era imposible.

Gritos de horror callados por la trágica muerte. Espanto, estertores. I silencio. I otra vez los gritos de los otros a quienes les llegaba el turno. Uno grita:

-No matá a mí... Yo dominiquénl...

-No matá... tomá cuátt (ofrecía dinero).

Gritaba un soldado, ebrio, endemoniado:

-Levanta el brazo... pa’matá pronto!... maldito "mañé!"

-Ah, bon dieu !... y caía.

Los puñales continuaban la siega, como en una vasta era. Los segadores eran mozos del campo que antes de soldados habían aprendido en sus aldeas a destripar verracos. Toda esa arte surgía ahora, trágica, implacable.

Uno gritaba:

-No mata, Pié... no me matá!...

¡¡Cállate, negro el diablo!...

Y... seguía la música sorda de los puñales bajo sol, mientras huían, asustadas, las abejas de los apiarios.

Sol de las diez, bravo, urente, sol de la Línea Noroeste, mientras sucumbe todo un pueblo, que cae como las espigas de un inmenso maizal.

-Muchachos! Pa’lante!... Pa’acabá con estos negros, con esta "garrapata", que se han cojío la tierra de los dominicanos! Pa'lante! 
El Sargento gritaba. Dentro de su embriaguez, en el momento del sacrificio de los negros de Haití, inexplicablemente venía a su mente algo que surgía del subconsciente: "estos negros, son bueno... Pero son ladrone! Deben morir!"

I así fue la vendimia roja. I como la quería el Capitán, como la quería el amo del Capitán y de todos: el amo de la República Dominicana.

--Carajo! decía un sargento de Mao --ojos de fiera, modales burdos, pelambre rala, un "colorao"-: Carajoooo!... voy a recoidai mi tiempo, cuando ei Generai asaitó la Foitaleza de Santiago... que peleamo jata con lo diente!... Látima que eto maidito "mañese" no pelean!... Pero lo que voy a hacé con eta "cotorrita"... Tendrán que nombraime "Generai!" (pp. 32-33)

Los trabajos críticos o meta-texuales han dado mucha importancia al discurso sobre la identidad, sobro todo al aspecto lingüístico. La palabra perejil es la marca más notable de la discriminación, usada sobre todo en las novelas de los autores haitianos, pero también, corriente entre los dominicanos con respecto a los haitianos.

En ese sentido, quiero destacar el trabajo de Aurea María Sotomayor-Miletti, (2011) "Pronunciar "perejil" en el río Masacre", quien afirma:

"Perejil" es la palabra cuyo valor social, al ser emitida, equivale a sobrevivir o a morir dependiendo de cómo se pronuncie bajo un estado de terror donde el intercambio lingüístico entre haitianos y dominicanos, además de la mutua influencia entre español y creole, va impactando paulatinamente la "pureza" lingüística del español que el estado dominicano desea imponer como lengua única y legítima para consolidarse." (p. 186)

También, en la tesis doctoral intitulada La narrativa y el discurso sobre la identidad nacional dominicana de Hayden Carrón Namnún (2009), para quien el discurso de la identidad fue un arma utilizada por
Trujillo para formar y animar las bandas asesinas, se expone:

El Masacre se pasa a pie es una novela-testimonio que trata sobre uno de los períodos más oscuros de la dictadura de Trujillo: el asesinato de entre doce y veinte mil haitianos en la franja fronteriza y en la región Cibao en el año 1937. Con el propósito de "blanquear" la frontera e impedir la "invasión" de los negros haitianos (que generalmente eran requeridos para trabajar en los ingenios azucareros), el régimen dispuso la puesta en libertad de presos con crímenes de sangre y reclutó entre las aldeas un gran número de "reservistas" que, armados y dirigidos por militares, formaron sobre la identidad dominicana bandas cuyo único objetivo era asesinar a la mayor cantidad de haitianos que encontraran a su paso. (p. 260)

Numerosos autores estudian, desde diversas perspectivas, el discurso de la identidad como uno de los elementos fundamentales del ser dominicano: Dipp, H. T. (1992), Raza e historia en Santo Domingo: los origenes del prejuicio racial en América; El otro del nosotros: Informe de investigación acerca del prejuicio antihaitiano en la ciudad de Santiago, de la República Dominicana; un aporte a la comprensión y al acercamiento de dos pueblos; Deive, C. E. (1992), Vodú y magia en Santo Domingo; Deive, C. E. (2013), ¿Y tu abuela dónde está? El negro en la historia y cultura dominicanas; Persinal, C. A. (2010), Encuentros y desencuentros de la cultura dominicana; Franco, F. J. (1997), Sobre racismo y antihaitianismo y otros ensayos; Rosario Fernández, Reina (2016), Raíces de la identidad dominicana.

\section{La vida y el discurso}

Los discursos antes mencionados y narrados en la obra El Masacre se pasa a pie, en el régimen tiránico de Trujillo estaban integrados al drama social del pueblo dominicano y el haitiano, y al drama personal de Freddy Prestol Castillo durante esa masacre y durante los treinta años que ese dictador gobernó en nuestro país. 
Por tanto, sería recomendable iniciar la lectura de esa obra destacando la situación de acoso e impotencia a la que estaba sometido el juez, así como la complicidad de la judicatura en la época de Trujillo. En estilo autobiográfico, en el siguiente párrafo, el autor ofrece un testimonio conmovedor acerca del estado de aislamiento y acorralamiento en que se encontraba antes de desertar del cargo de juez de intrusión y ser condenado a cinco ańos de prisión:

Héme aquí todavía en estas tierras. Soy un testigo mudo. Un testigo cómplice. Estoy acusado por mi conciencia. ¿Cuál es mi deber? ¡Acusar! ¡Debo irme! ¿Y por qué continúo en esta aldea, recluído en una choza, aislado, sumergido en la soledad de sus noches, frente a la Inmensa sabana? Intento a veces leer, bajo luz mortecina de kerosene, el Boletín Judicial, órgano de la Suprema Corte de mi país, para no permanecer ajeno a la evolución de nuestra jurisprudencia. No tengo con quien dialogar. Desde temprano las casas de la aldea están cerradas y yo me he retirado del hotelucho de dońa Francina, a quien detesto por inquisidora y dúplice, de quien se barrunta que es un espía del Gobierno para hacer delaciones de los funcionarios que puedan criticar estos acontecimientos. Mi compañero, el juez, un excelente caballero, ha optado por envenenarse cada día con alcohol. Tan pronto terminan las audiencias de los pocos casos que acontecen aquí —algunos robos, heridas, sustracciones de muchachas-, el juez va a juntarse con un oficial del Ejército, perteneciente a una aristocrática familia de Puerto Plata, hombre fino, que repugna todo esto, y quien también ha resuelto soportar este ambiente bajo una permanente borrachera. Estoy solo. (p. 174)

Quisiera terminar con esta reflexión: no existe separación entre vida y discurso. Ambos son aspectos de un solo vivir. La nación, la identidad y la migración no solo son textos e ideas; son acciones vividas diariamente por los sujetos, como situaciones liberadoras o esclavizadoras.
En una dictadura, como la de Trujillo, son conceptos y realidades que envilecen y destruyen al ser humano. Es la gran lección que nos deja el discurso de El Masacre se pasa a pie y el aparato discursivo de las relaciones dominico-haitianas, cuando se pone al servicio de intereses e ideologías opresores.

\section{Referencias}

Carrón Namnún, H. La narrativa y el discurso sobre la identidad nacional dominicana (tesis doctoral inédita). Universidad Autónoma de Madrid, Facultad de Filosofía y Letras, Departamento de Filología Española. Madrid, España. [Fecha de lectura: 12-06-2009].

Carvajal, J. (2015). Haití y una novela de Matos Moquete (I). [Entrada en un blog] Recuperado de http://youmethemus.blogspot.com/2015/08/ haiti-y-una-novela-de-matos-moquete-i.html

Conde Sturla, P. (2019, 1 de julio). La masacre. Acento.com.do. Recuperado de https://acento. com.do/2019/opinion/8699926-la-masacre/

Genette, G. (1982). Palimsestes, Paris, Francia: Editions du Seuil.

Matos Moquete, M. (2005). Estudios translingüisticos. Santo Domingo, República Dominicana: Editora Búho.

Moya Pons, F. (1996). Las tres fronteras: introducción a la frontera domínico-haitiana. En W. Lozano. (Ed). La cuestión haitiana en Santo Domingo (pp. 17-31). Santo Domingo, República Dominicana: FLACSO.

Pérez Carrión, I. (septiembre 29, 2014). Julia Álvarez: Matanza de haitianos de 1937 es hecho que no ha sido bien abordado ni reparado por RD. Acento.com. Recuperado de https://acento. com.do/2014/actualidad/8178824-julia-alvarezmatanza-de-haitianos-de-1937-es-hecho-que-noha-sido-bien-abordado-ni-reparado-por-rd/

Sotomayor-Miletti, A. (2011). Pronunciar "perejil" en el río Masacre. University of Pittsburgh. Cuadernos de literatura 30(julio-diciembre), 184-201. 


\section{Datos de filiación}

Manuel Matos Moquete. Nació el 6 de abril de 1944 en Tamayo, República Dominicana. Doctorado en Literatura, Universidad París viII. Profesor jubilado de la UASD y de INTEC. Miembro de Número de la Academia Dominicana de la Lengua. Miembro de Número de la Academia de Ciencias de la República Dominicana. Premio Nacional de Literatura 2019. Líneas de investigación: lingüística, Análisis del discurso; literatura dominicana. 